\title{
Comunidades de aprendizaje y su avance en la interculturalización de la Educación Superior en la Universidad de las Regiones Autónomas de la Costa Caribe Nicaragüense
}

\author{
Learning communities and their growth in the interculturalization of higher education at the University of \\ the Autonomous Regions of the Nicaraguan Caribbean Coast, Bilwi Campus
}

Yader Galo-Sacasa ${ }^{1}$

\section{Resumen}

El ensayo pretende hacer una revisión sobre el avance de la función comunidades de aprendizaje en el proceso de interculturalización de la educación superior de la URACCAN recinto Bilwi. Para ello, se realizó una descripción general de universidad, seguidamente se revisó el quehacer de la función comunidades de aprendizaje en materia de interculturalización de la educación superior y diálogo de saberes. La información se obtuvo de la revisión del informe de gestión institucional del recinto Bilwi para el 2018 y su cumplimiento con lo establecido en el plan estratégico (2015-2019). Se muestran avances significativos en materia de la interculturalización de la educación superior, mismos que pueden ser evidenciados en el marco filosófico y normativas de la universidad. En el recinto Bilwi, desde la función comunidades de aprendizaje, se procura el cumplimiento del marco filosófico, tratando de acercar las brechas de accesos y permanencia a una educación superior pertinente y de calidad entre personas de orígenes diversos. A pesar de lo anterior, se requiere continuar trabajando en la concientización del personal que labora en la institución, especialmente el personal de tiempo horario, con el fin de romper el paradigma hegemónico de las universidades convencionales en lo referente al rol del docente. De igual manera, se hace necesario continuar avanzando en la creación y recreación de nuevos saberes que beneficie tanto a las comunidades indígenas como a la universidad y la sociedad en general.

Palabras clave: Diálogo de saberes; interculturalidad; interculturalización de la educación superior; URACCAN.

\section{Abstract}

The essay intends to review the progress of the learning communities function in the process of interculturalization of higher education at URACCAN, Bilwi Campus. For this, a general description of the university was made, then the task of the learning communities function in the field of interculturalization of higher education and knowings dialogue was reviewed. The information was obtained from the review of the institutional management report of Bilwi Campus for 2018 and its compliance with the provisions of the strategic plan (2015-2019). Significant advances are shown in the interculturalization of higher education, which can be evidenced in the philosophical and normative framework of the university. In Bilwi campus, from the function of learning communities, compliance with the philosophical framework

\footnotetext{
1 Máster en Desarrollo con Identidad con Mención en Gobernabilidad, Territorialidad y Manejo de Bosques. Coordinador de Evaluación Institucional de la Universidad de las Regiones Autónomas de la Costa Caribe Nicaragüense-Recinto Universitario Bilwi. Correo yader.galo@uraccan.edu.ni ORCID: https://orcid. org//0000-0002-1389-0730
} 
is sought, trying to bring access gaps and permanence to a relevant and quality higher education among people of diverse backgrounds. In spite of the above, it is necessary to continue working on the awareness of the staff working in the institution, especially the time-staff, in order to break the hegemonic paradigm of conventional universities in relation to the role of the professor. Similarly, it is necessary to continue advancing in the creation and recreation of new knowledge that benefits both indigenous communities and the university and society in general.

Keywords: Knowings Dialogue; Interculturality; Interculturalization of Higher Education; URACCAN.

\section{Introducción}

Durante años, los pueblos indígenas y afrodescendientes han luchado por el reconocimiento pleno de sus derechos individuales y colectivos. En las últimas décadas se aprecian avances significativos en materia de derechos, mismos que han sido consagrados en instrumentos jurídicos internacionales, tal es el caso del Convenio 169 de la OIT y la declaración de las Naciones Unidas para los Derechos de los Pueblos Indígenas. En ambos casos se reconocen derechos a la educación con pertinencia. De igual manera, se aprecia un mayor reconocimiento de sus derechos colectivos en instrumentos jurídicos, como lo son algunas constituciones políticas y leyes específicas en muchos de los países latinoamericanos.

En materia de educación, las luchas e iniciativas de los pueblos indígenas han dado lugar a la creación de universidades para/por/con pueblos indígenas y afrodescendientes. Los avances han transitado desde buscar la inclusión de individuos indígenas y afrodescendientes en instituciones de educación superior convencionales hasta la creación de universidades indígenas, interculturales y comunitarias que responden a las necesidades particulares de los pueblos.

En este sentido, la URACCAN es una institución de educación superior fundamentada en la interculturalidad, el diálogo de saberes, las cosmovisiones y espiritualidades de los pueblos; la participación de las sabias, sabios, ancianas, ancianos, autoridades tradicionales y no tradicionales en la búsqueda y recreación de nuevos paradigmas y enfoques metodológicos en la generación de conocimientos para la construcción del buen vivir y las ciudadanías interculturales de género (URACCAN, 2014). Así pues, la URACCAN no es solo un proyecto educativo, sino que es un proyecto político que busca fortalecer el proceso autonómico regional de la Costa Caribe nicaragüense, lo cual conlleva a desarrollar vínculos de colaboración intercultural con pueblos indígenas, afrodescendientes y comunidades étnicas. Por tanto, desde su plan estratégico (2015-2019) determina su quehacer en base a sus funciones sustantivas: i) Comunidades de Aprendizajes, ii) Creación y Recreación de Conocimientos Saberes y Prácticas, iii) Acompañamiento e Incidencia Social Comunitaria, iv) Gestión y Comunicación Intercultural, v) Cooperación, Solidaridad y Complementariedad, definido en el nuevo plan estratégico 2015 -2019.

A la luz de lo anterior, el escrito pretende realizar una revisión sobre el avance de la URACCAN recinto Bilwi, desde la función comunidades de aprendizaje en el proceso de interculturalización de la educación superior. El documento realiza una descripción general de la URACCAN, seguidamente se revisa el quehacer de la función comunidades de aprendizaje en materia de interculturalización de la educación superior y diálogo de saberes, por último, se comparten reflexiones finales. 


\section{Desarrollo}

\section{Descripción general de la institución de la Educación Superior}

La creación de la Universidad de las Regiones Autónomas de la Costa Caribe Nicaragüense (URACCAN) como proyecto político educativo de los pueblos y comunidades indígenas, afrodescendientes y mestizas del Caribe nicaragüense, ha implicado una serie de esfuerzos organizativos de gestión académica e incidencia política y social a nivel regional, nacional e internacional. Tras varias iniciativas fallidas de establecimiento de programas de Educación Superior a distancia con la UNAN-Managua en la década del 70, nuestros fundadores optaron por impulsar un modelo propio de Universidad, que respondiera a la particularidad geográfica, sociocultural, política, económica y ambiental de la región, promoviera la unidad en la diversidad y fortaleciera el ejercicio de los derechos constitucionales y autonómicos (derivados de la Ley 28 o Estatuto de Autonomía de las Regiones de la Costa Atlántica de Nicaragua).

En la creación de la URACCAN, existen importantes hitos históricos. Los fundadores de la Universidad organizados en la "Asociación Pro-URACCAN, presentaron ante el Consejo Nacional de Universidades (CNU) su proyecto de creación en 1990. El 6 de marzo de 1992 fue aprobado. El 3 de junio de 1993, la Asamblea Nacional otorga la personería jurídica a la Universidad, mediante el Decreto 602 publicado en La Gaceta número 104. En 1994, el Consejo Técnico de la URACCAN elaboró normativa sobre la organización y funcionamiento de los dos primeros años de funcionamiento y celebró las primeras elecciones de autoridades: rectoría y vicerrectorías de recinto. En enero de 1995, se inician las actividades académicas en los recintos Bilwi, Las Minas (Siuna), Bluefields y las extensiones en Waspam, Rosita y Bonanza. Estas sedes se ubican en las principales zonas etnolingüísticas de la Región Autónoma de la Costa Caribe Norte (RACCN) y Sur (RACCS).

A partir de 1996, conforme el Art. 2 de la Ley 2181, la URACCAN recibe financiamiento Estatal mediante el 6\% del Presupuesto General de la República, además pasa a ser miembro pleno del CNU. En 1997, se registró y publicó el estatuto de la Universidad (certificación número 1220) en las páginas 249 a 267 del Tomo II, Libro Quinto de Registro de Asociaciones del Departamento de Registro y Control del Ministerio de Gobernación. En este año, se establece la extensión Nueva Guinea del Recinto de Bluefields. En el 2001, por su crecimiento en estudiantes y carreras, Nueva Guinea pasa a ser recinto.

En el año 2001, los Consejos Regionales Autónomos reconocen a la Universidad como "Patrimonio de los Pueblos del Caribe nicaragüense", también se elabora participativamente el primer Plan Estratégico Institucional (PEI 2001-2005). En el 2002, se crea la extensión de Waslala del recinto Las Minas. En el 2006, con la aprobación de la Ley General de Educación (Ley 582), se reconoce el Sub-sistema Educativo Autonómico Regional (SEAR) como parte del Sistema Educativo Nacional (Título II, Capítulo I, Artículo 12 y Capítulo IV, Artículos 38 al 42) y a la URACCAN su carácter comunitario e interés público regional, reafirmando su financiamiento vía Presupuesto General de la República (Capítulo VI, Artículo 49). En el 2007, el Consejo Universitario de la URACCAN (CUU), aprueba el segundo Plan Estratégico Institucional (PEI 2008-2012), derivado de otro proceso de reflexión y análisis ampliamente participativo.

La lucha por el reconocimiento de una educación pertinente para los pueblos indígenas y afrodescendientes nos ha llevado a navegar por diversas experiencias de Educación Superior por/para/con pueblos indígenas en América Latina. La experiencia de la URACCAN se enmarca en la creación de un modelo de universidad intercultural, como medida para responder al rezago del Estado de responder en primera instancia a la demanda de acceso a la educación superior para los pobladores de la Costa Caribe nicaragüense y segundo, a la necesidad de una formación pertinente al contexto cultural, respetuoso de la diversidad y cosmovisiones de los diferentes pueblos indígenas y afrodescendientes. 


\section{Comunidades de Aprendizaje}

Desde el Plan Estratégico Institucional 2015-2019, se menciona que la función “Comunidades de aprendizajes" comprende todas las actividades orientadas a la creación, recreación, diseminación e intercambio de conocimientos, saberes, valores y prácticas desde dos vías: la interacción entre conocimientos locales, ancestrales y conocimientos occidentales.

Desde la función comunidades de aprendizaje en el recinto Bilwi, se atienden un total de $1335^{2}$ estudiantes de los cuales el 58 por ciento son mujeres. Los datos desagregados por etnia muestran que el 77 por ciento se identifican como miskitu, 17 por ciento como mestizos y un 6 por ciento entre creole, mayangna y extranjeros. Estos datos muestran la diversidad étnica y cultural en las aulas de clases de URACCAN recinto Bilwi.

Esta diversidad cultural y étnica conlleva a tener diferentes cosmovisiones del mundo, lo cual nos permite pensar que la construcción del conocimiento en sí debe partir del reconocimiento de la pluralidad de conocimientos. De hecho, la producción del conocimiento dependerá en gran medida del contexto social donde se produce. La descalificación de los modos de producción de conocimiento y de acumulación de los pueblos indígenas, es resultado de la herencia colonial (Mato, 2008). En este sentido, las actividades de la función, comunidades de aprendizaje son los espacios conjuntos de diálogos de saberes, aplicando metodologías socio-constructivistas y participativas, asegurando el balance teórico-práctico.

Lo anterior tiene congruencia con la declaración de la CRES (2008), misma que en su apartado $C_{3}$ incita a iniciar procesos de transformación de la educación superior en pro de ser más interculturales de tal manera que no se tenga una visión solo de inclusión de individuos a las IES convencionales, sino transformar a éstas para que sean más pertinentes con la diversidad cultural. La URACCAN a través de su modelo pedagógico, busca la formación integral y su relación con las nuevas tecnologías, lo cual lleva necesariamente a la consideración de la interculturalidad y la interdisciplinaridad como ejes dinámicos de todo este proceso de enseñanza-aprendizaje (URACCAN, 2004).

El proceso de enseñanza por aprendizaje en el recinto Bilwi, está a cargo de 112 docentes de los cuales el 59 por ciento tienen un contrato de horarios. En lo referente a la desagregación por etnia se muestra que el 66 por ciento se identifica como miskitu, un 33 por ciento como mestizo y 1 por ciento como creole. Si bien la representación étnica de los docentes es coherente con la diversidad étnica de los estudiantes matriculados, el alto porcentaje de docente horarios sugiere un reto significativo para el recinto Bilwi, pues, aunque este personal es capacitado en el modelo de universidad que pregonamos, la relación contractual limita su compromiso e identidad institucional.

Para la URACCAN (2014), la interculturalidad es concebida como un proceso permanente de construcción, establecimiento y fortalecimiento de espacios de diálogo, comunicación e interacción horizontal de doble vía, entre personas, comunidades y pueblos de diferentes culturas. Su finalidad es la promoción y práctica de la equidad, el respeto, la comprensión, la aceptación mutua y la creación de sinergias para el establecimiento de sociedades inclusivas, no discriminatorias y libres de racismo (Hooker, 2018).

El proceso de interculturalización de la educación superior desde la URACCAN ha conducido a crear oportunidades de acceso, para los pueblos indígenas, afrodescendientes y comunidades étnicas ${ }^{3}$ a una educación de calidad y pertinente a su contexto, su cultura, donde se revaloriza la identidad étnica y el saber

\footnotetext{
2 Estadísticas Registro Académico correspondiente al primer trimestre del 2018.

3 Me refiero a todos aquellos que no se consideran ni indígenas, ni afrodescendientes. Incluye extranjeros.
} 
ancestral. Esto se evidencia en su oferta académica que incluye carreras como: Ingeniería Agroforestal, Sociología con mención en Autonomía, Medicina Intercultural, Psicología en contextos multiculturales, Técnico Superior en Gestión Cultural, Técnico Superior en Enfermería Intercultural, entre otras; las cuales responden a las necesidades de la Costa Caribe nicaragüenses y que no son asumidas desde las IES convencional del país. Los conocimientos, historias, visiones del mundo, vivencias espirituales, las lenguas y la relación armónica con la naturaleza, son parte de nuestro modelo educativo (Hooker, 2018).

De igual manera en el proceso de interculturalización de la educación superior, en el año 2010 el $\mathrm{CUU}^{4}$ orienta la trasversalización, en cada una de las carreras ofrecidas por la institución, del abordaje de las siguientes asignaturas: Recursos Naturales de la Costa Caribe nicaragüense, Lengua Indígena ${ }^{5}$, Salud Sexual y Derechos Reproductivos, Ciudadanía Intercultural e Historia de la Costa Caribe nicaragüense.

Es importante tener en cuenta que interculturalizar la educación superior conlleva a reconocer que toda sociedad multiétnica no sólo se estructura jerárquicamente a partir de la diferencia étnica, sino también de la diferencia sexual y de los sistemas sexo-genéricos, (URACCAN, 2018). En este sentido, la asignatura Salud Sexual y Derechos Reproductivos, así como Ciudadanías Interculturales procuran acciones que contribuyan a transformar patrones culturales negativos como la discriminación, exclusión y violencia principalmente hacia las mujeres.

En el caso de la asignatura Lengua Indígena, específicamente miskitu ${ }^{6}$, está diseñada para miskitu, hablantes, procurando fortalecer la escritura, lo cual es congruente con lo establecido en la declaración final de la CRES (2018), en la que se menciona "es fundamental promover y facilitar el aprendizaje de las lenguas de pueblos indígenas, afrodescendientes y su uso efectivo..." En definitiva, se requiere fortalecer la lengua materna en miskitu hablantes, pues por el contexto multicultural de la Costa Caribe nicaragüense, se realizan muchos préstamos lingüísticos (principalmente del español) lo cual, en cierta medida, podría conducir a una asimilación lingüística. Sin embargo y teniendo en cuenta ese contexto multicultural, multiétnico y considerando que por la hegemonía del español muchos miskitus, principalmente la nueva generación, han optado por no aprender la lengua, se requiere que desde la URACCAN se ofrezcan cursos diferenciados de lengua materna, que permita a los no hablantes -miskitu y de otras etnias-aprender la lengua, lo cual contribuiría a promover la perpetuidad de la misma y reconocer la importancia del miskitu para fortalecimiento de la cultura.

Igual de importante para la interculturalización de la educación superior es la incorporación del diálogo de saberes y el reconocimiento de la diversidad de valores y modos de aprendizaje. Desde URACCAN se considera que para la construcción de sociedades de conocimientos se requiere de procesos de articulación entre las instancias de la Universidad, así como con actores sociales y comunidades. La política de articulación define:

La articulación es un proceso de diálogo de saberes implementado por la universidad con las comunidades y actores sociales; encaminados al ordenamiento de desarrollo regional y fortalecimiento de los sistemas autonómicos y la promoción del patrimonio cultural desde un enfoque de equidad de género, para la construcción colectiva del buen vivir de los pueblos, el respeto, equilibrio y armonía con la Madre Tierra a nivel nacional e internacional (URACCAN, 2016:24).

4 Tercera sesión del CUU, desarrollada en Bilwi, Kamla en diciembre del 2010. Acuerdo número 12

5 Según el recinto se imparten: Miskitu, Mayangna o Creole. En el caso particular de Bilwi se oferta Miskitu.

6 No conozco el programa de Mayangna y Creol, por lo que no puedo hacer juicio al respecto. 
Un diálogo de saberes que no se limita a la mutua escucha de la exposición de conocimientos entre academia y personas de conocimientos, sino que busca el buen vivir personal, familiar y comunitario, desde la armonía entre el conocimiento propio y el conocimiento occidental, a través de la creación, recreación, diseminación e intercambio de conocimientos, sentires, sabidurías, saberes y haceres (URACCAN, 2017).

Este diálogo de saberes plasmado desde la filosofía de la URACCAN, definitivamente conlleva a colaboraciones interculturales, misma que como lo menciona Mato (2016), procuran el desarrollo de experiencias sostenibles de producción y aplicación del conocimiento, aprendizajes del conocimiento, desarrollo de destrezas y competencias y para la puesta en práctica de acciones en beneficios de pueblos indígenas y sociedades en general.

En este sentido, el Plan Estratégico Institucional establece, en la función comunidades de aprendizaje, como una de sus metas la aplicación de metodologías participativas que garanticen el diálogo de saberes y el balance teórico-práctico con perspectiva intercultural de género. Dentro de los indicadores de cumplimiento de la meta antes descrita esta la integración de sabias y sabios, médicos tradicionales y líderes/lideresas en el proceso enseñanza aprendizaje. Esto requirió que la URACCAN definiera criterios para identificar sabios, sabias, líderes y lideresas ${ }^{7}$. Con los criterios definidos se procedió a realizar el diagnóstico de sabios y sabias por cada uno de los recintos. En el caso particular del recinto Bilwi, se identificaron un total de 41 sabios y sabias, mismos que son reconocidos en sus comunidades y/o barrios como curanderos y parteras principalmente.

El informe de gestión institucional del recinto Bilwi del primer trimestre 2018, muestra que se ha contado con la participación de sabios y sabias en los procesos de enseñanza aprendizaje. Estos participaron a través de charlas, conversatorios y talleres, principalmente en las carreras de Sociología, Gestión Cultural y Medicina Intercultural. De igual manera, desde la carrera Ingeniería Agroforestal se desarrollaron giras prácticas en la que estudiantes viajaron a comunidades indígenas con el fin de conocer las experiencias comunitarias en materia de manejo de cultivos y gobernanza.

Generalmente, este tipo de diálogo de saberes se concentran en la diseminación e intercambio de conocimientos, sentires, sabidurías, saberes y haceres. Se requiere continuar trabajando en la Creación, Recreación de Conocimientos, especialmente desde la academia, puesto que desde la función AISC ${ }^{8}$, se cuenta con experiencias al respecto, donde se acompañó a las comunidades para en conjunto construir planes de vidas ${ }^{9} \mathrm{y}$ estatutos comunitarios ${ }^{10}$.

Uno de los retos en el tema de la inclusión de los sabios y sabias a los procesos de enseñanza aprendizaje es la remuneración (principalmente con fondos del Estado) de manera equitativa, al carecer de títulos universitarios. A pesar de lo anterior desde el recinto se buscan alternativas y en el caso de la Escuela de liderazgo se contrataron dos ancianos de la comunidad de Kamla, quienes fungen como consejeros del grupo de estudiantes que en su mayoría provienen de comunidades indígenas. Estos ancianos son remunerados a través de fondos propios y en vez de un contrato se les realiza carta ${ }^{11}$ de entendimiento.

En lo referente a las prácticas y pasantías, desde las coordinaciones de carrera se elaboró un plan en el que se identifican aliados estratégicos para el desarrollo de las mismas. En el informe de gestión institucional

\footnotetext{
7 Estrategia de Participación de Sabios y Sabias en los Procesos Pedagógicos del Diálogo de Saberes de la Universidad Comunitaria Intercultural. Aprobada en el CUU 2017, Bilwi.

8 Acompañamiento e Incidencia Social Comunitaria.

9 Plan de vida de la comunidad de Tuapi.

${ }^{10}$ Estatutos de las comunidades de Kamla y Sumu Bila.

${ }^{11}$ Esta carta de entendimiento no requiere de títulos universitarios.
} 
para el primer trimestre, se reporta que los aliados inidentificados para el 2018, son instituciones estatales y empresas privadas, quienes de buena voluntad admiten a los estudiantes para que consoliden el conocimiento teórico con el práctico. Pero este conocimiento se refiere a lo científico (lo técnico), sin tener en cuenta el conocimiento ancestral.

En este sentido, se requiere promover la firma de convenios con las comunidades indígenas y/o con los Gobiernos Territorios Indígenas (GTI) de la región con el fin de tenerlas en cuenta como escenario donde los estudiantes de las diversas carreras concreten el desarrollar de sus pasantías, lo cual podría contribuir a fortalecer la creación y recreación de conocimientos de cara al fortalecimiento del diálogo de saberes.

Lo anterior sugiere otro reto importante, el cual tiene que ver con la disponibilidad de fondos para la movilización y estadía de estudiantes a las diferentes comunidades y GTI. Para el 2018, el 74 por ciento de los fondos asignados al recinto Bilwi por el Ministerio de Hacienda y Crédito Público, se destinaron al pago de planilla del personal permanente y de los docentes horarios.

En este sentido, las prácticas y pasantías son asumidas desde los Fondos Propios ${ }^{12}$ del recinto, mismos que además de ser insuficientes (se realizan proyecciones de generación de un poco menos del 16\% del presupuesto general del recinto) no se tiene certeza de disponer de ellos en el tiempo y la cantidad proyectada. Esta situación dificulta que se consoliden los procesos de diálogos de saberes en/con la comunidad, pues como lo plantea Mato (2016), el reto es salir de las aulas de clase, aprender en los espacios apropiados lo que estas personas indiquen. La insuficiente o irregular asignación presupuestaría para prácticas y pasantías, es un asunto a considerar seriamente antes de la firma de convenios con comunidades indígenas, pues de no poderse materializar lo pactado se podría generar desconfianza de parte de la comunidad hacia la universidad al considerar la falta de seriedad con la que el recinto toma acuerdos.

\section{Conclusiones}

Desde su creación, la URACCAN busca reivindicar los derechos colectivos del pueblo costeño, a una educación superior que procurara no sólo el acceso, sino el reconocimiento de las diversidades étnicas, el respeto y promoción de la cultura, el fortalecimiento del proceso autonómico regional y la integración nacional.

Para lograr lo anterior, la URACCAN ha tenido que manejarse en dos aguas. Por un lado, cumplir los requisitos de ley para constituirse como universidad y, por otro lado, impulsar un modelo de universidad diferente a las IES convencionales presentes en el país. Esto último ha sido una tarea constante, pues por tratarse de un paradigma diferente se requiere realizar mucho trabajo de incidencia y educación a las instancias gubernamentales con el fin que comprendan el espíritu del modelo comunitario e intercultural.

En la actualidad los avances en el tema de la interculturalización de la educación superior en la URACCAN son significativos, a tal punto de ser referentes a nivel nacional e internacional. Estos avances se evidencian en el marco filosófico, las políticas y normativas que guían el quehacer institucional. De igual manera se evidencian en incidencia realizadas en el ámbito nacional e internacional para impulsar el modelo de universidad comunitaria e intercultural.

\footnotetext{
${ }^{12}$ Fondos generados por el pago de servicios prestados por el recinto.
} 
En el recinto Bilwi, desde la función comunidades de aprendizaje, se aprecian avances significativos en materia de la efectiva interculturalización de la educación superior, lo cual se evidencia en la diversidad étnica de los estudiantes. Se procura acercar las brechas de accesos y permanencia a una educación superior pertinente y de calidad entre personas de orígenes diversos.

Esta pertinencia se evidencia en la inclusión de elementos culturales propios en los currículos de las carreras ofertadas. Las carreras ofertadas son una demanda no solo del mercado laboral, sino de la misma sociedad costeña, en demanda de satisfacer las necesidades que desde el Estado no se han podido concretar. Por ejemplo, enfermedades culturales como el Grisi Siknis, difícilmente serán diagnosticadas y tratadas debidamente por médicos formados en IES convencionales, por eso era necesario crear la carrera de Medicina Intercultural, donde los médicos sean capaces de reconocer y respetar el saber ancestral, para poder trabajar de manera colaborativa con médicos tradicionales para solucionar este tipo de situaciones.

Sin embargo, la interculturalización es un proceso en constante construcción y se requiere continuar trabajando en la concientización del personal que labora en la institución. Esto es principalmente necesario con los docentes horarios y algunos de tiempo completo. Este personal es capacitado en el modelo de universidad que pregonamos, sin embargo, aún se perciben resistencia en el cambio de actitud para romper el paradigma hegemónico de las universidades convencionales en lo referente al rol del docente.

En lo referente al diálogo de saberes, desde la función comunidades de aprendizaje se avanza en la diseminación e intercambio conocimientos y saberes. Es necesario continuar avanzando en la creación y recreación de nuevos saberes que beneficie tanto a las comunidades indígenas como a la universidad y la sociedad en general. Esta es una tarea en la que desde la función comunidades de aprendizaje, se tienen limitaciones principalmente del tipo económico y de flexibilidad administrativas para la contratación de sabios y sabias, así como para la movilización y estadía de pasantes en comunidades y/o GTI.

\section{Lista de referencias}

Asamblea Nacional. (1987). Estatuto de Autonomía de las Regiones Autónomas de la Costa Atlántica de Nicaragua, Ley No. 28. La Gaceta, Diario Oficial No. 186. Managua, Nicaragua.

Asamblea Nacional. (2000). Constitución Política de Nicaragua. Managua, Nicaragua.

Asamblea Nacional. (2006). Ley General de Educación, Ley 582. Recuperado de file://C:/Users/Usanger/ Downloads/Ley_Educ_582\%20(1).pdf

Asamblea Nacional.(2011).Ley Creadoradel Sistema Nacional ParaelAseguramientodela CalidaddelaEducación y Reguladora del Consejo Nacional de Evaluación y Acreditación, Ley 704. (2011). Recuperado de https:// es.scribd.com/doc/89251271/Ley-704-Ley-creadora-aseguramiento-de-la-calidadde-la-educacion

Hooker-Blandford, A. (2018). Conferencia: Interculturalidad e internacionalización desde los pueblos de América Latina y el Caribe. CRES 2018.

Mato, D. (2008). No hay saber "universal", la colaboración intercultural es imprescindible. Revista Alteridades, 18(35), 101-116. 
Mato, D. (2016). Educación Superior y Pueblos Indígenas en América Latina: Del "Diálogo de Saberes" a la construcción de modalidades sostenibles de Colaboración Intercultural". Revista CIsen Tramas/Maepova, 4(2), 71-94.

URACCA. (2010). ESTATUTOS de la Universidad de las Regiones Autónomas de la Costa Caribe Nicaragüense. Managua: URACCAN.

URACCAN (2017). Política de Acompañamiento Comunitario Intercultural de la Universidad de las Regiones Autónomas de la Costa Caribe Nicaragüense. Managua: URACCAN.

URACCAN. (2004). Modelo pedagógico de la Universidad de las Regiones Autónomas de la Costa Caribe Nicaragüense. Managua: URACCAN.

URACCAN. (2014). Plan Estratégico Institucional 2015-2019 de la Universidad de las Regiones Autónomas de la Costa Caribe Nicaragüense. Managua: URACCAN.

URACCAN. (2018). La perspectiva intercultural de género desde la mira de la Universidad de las Regiones Autónomas de la Costa Caribe Nicaragüense. Managua: URACCAN. 